This is an electronic reprint of the original article. This reprint may differ from the original in pagination and typographic detail.

Author(s): Tabacaru, G.; May, D. P.; Ärje, Juha; Chubarian, G.; Clark, H.; Kim, G. J.; Tribble, R. E.

Title: $\quad$ The rare isotope beams production at the Texas A\&M university Cyclotron Institute

Year: $\quad 2013$

Version:

Please cite the original version:

Tabacaru, G., May, D. P., Ärje, J., Chubarian, G., Clark, H., Kim, G. J., \& Tribble, R. E. (2013). The rare isotope beams production at the Texas A\&M university Cyclotron Institute. In Application of Accelerators in Research and Industry: Twenty-Second International Conference (pp. 507-510). American Institute of Physics. AIP

Conference Proceedings, 1525. https://doi.org/10.1063/1.4802380

All material supplied via JYX is protected by copyright and other intellectual property rights, and duplication or sale of all or part of any of the repository collections is not permitted, except that material may be duplicated by you for your research use or educational purposes in electronic or print form. You must obtain permission for any other use. Electronic or print copies may not be offered, whether for sale or otherwise to anyone who is not an authorised user. 


\section{AP $\mid \begin{aligned} & \text { Review of } \\ & \text { Scientific Instruments }\end{aligned}$}

Production of rare isotope beams at the Texas A\&M University Cyclotron Institutea)

G. Tabacaru, D. P. May, J. Arje, G. Chubarian, H. Clark, G. J. Kim, and R. E. Tribble

Citation: Review of Scientific Instruments 83, 02 A905 (2012); doi: 10.1063/1.3663272

View online: http://dx.doi.org/10.1063/1.3663272

View Table of Contents: http://scitation.aip.org/content/aip/journal/rsi/83/2?ver=pdfcov

Published by the AIP Publishing

\section{Articles you may be interested in}

The rare isotope beams production at the Texas A\&M university Cyclotron Institute

AIP Conf. Proc. 1525, 507 (2013); 10.1063/1.4802380

Application of 3D Code IBSimu for Designing an H - / D - Extraction System for the Texas A\&M Facility Upgrade AIP Conf. Proc. 1390, 439 (2011); 10.1063/1.3637415

The Upgrade Project at Texas A\&M University Cyclotron Institute: Update

AIP Conf. Proc. 1304, 425 (2010); 10.1063/1.3527239

The Upgrade Project at Texas A\&M Cyclotron Institute

AIP Conf. Proc. 972, 546 (2008); 10.1063/1.2870457

Radioactive Beams Using the AECR-U and the 88-Inch Cyclotron

AIP Conf. Proc. 749, 151 (2005); 10.1063/1.1893386

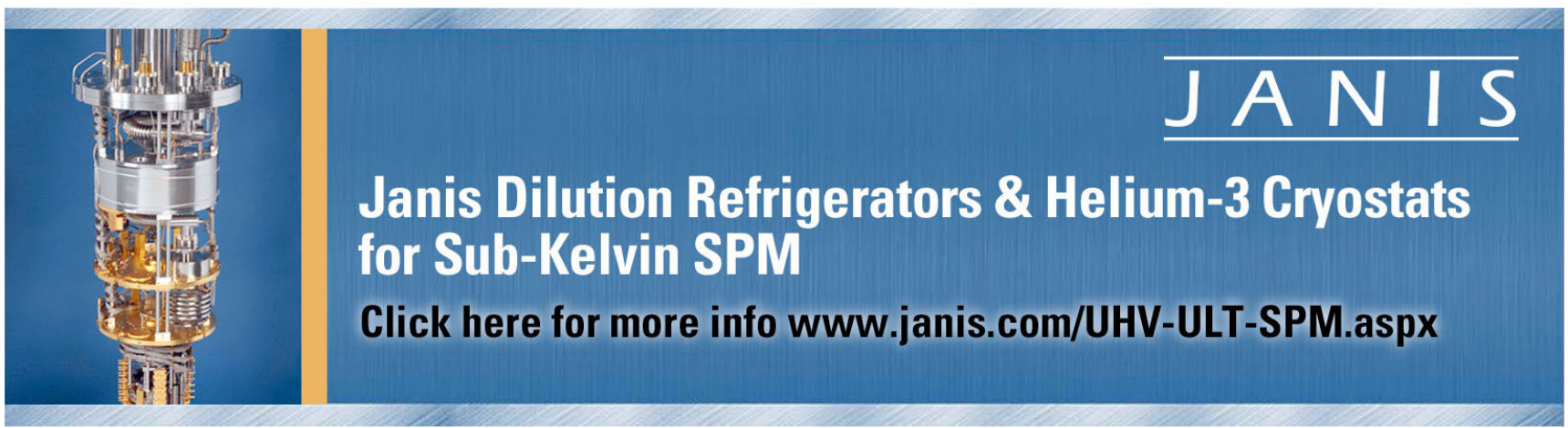




\title{
Production of rare isotope beams at the Texas A\&M University Cyclotron Institute ${ }^{\text {a) }}$
}

\author{
G. Tabacaru, ${ }^{1, b)}$ D. P. May, ${ }^{1}$ J. Arje, ${ }^{2}$ G. Chubarian, ${ }^{1}$ H. Clark, ${ }^{1}$ G. J. Kim,${ }^{1}$ \\ and R. E. Tribble ${ }^{1}$ \\ ${ }^{1}$ Cyclotron Institute, Texas A\&M University, College Station, Texas 77843-3366, USA \\ ${ }^{2}$ Accelerator Laboratory, University of Jyväskylä, Jyväskylä, Finland
}

(Presented 13 September 2011; received 13 September 2011; accepted 4 October 2011; published online 7 February 2012)

The Cyclotron Institute at Texas A\&M is currently configuring a scheme for the production of radioactive-ion beams that incorporates a light-ion guide and a heavy-ion guide coupled with an electron-cyclotron-resonance ion source constructed for charge-breeding. This scheme is part of an upgrade to the facility and is intended to produce radioactive beams suitable for injection into the K500 superconducting cyclotron. The current status of the project and details on the ion sources used in the project is presented. (C) 2012 American Institute of Physics. [doi:10.1063/1.3663272]

\section{INTRODUCTION}

Inside the nuclear physics community, there is growing interest in the use of beams of radioactive ions for experiments in the fields of nuclear astrophysics, nuclear thermodynamics, and nuclear structure. Many laboratories throughout the world have started various programs of upgrades in order to increase and diversify their capabilities to produce radioactive ion beams (RIBs) with sufficient intensities and energies to carry on sensitive experiments. The Cyclotron Institute at Texas A\&M University has radioactive-ion-beam capability with the momentum achromatic recoil spectrometer, but the energies and intensities of the secondary beams are limited by various constraints of the spectrometer itself and by the characteristics of the primary beam.

In 2005, the Cyclotron Institute started an upgrade project enabling the production and acceleration of RIBs. This will be based on coupling the two existing cyclotrons, the $\mathrm{K} 150$, or the old $88^{\prime \prime}$ cyclotron and the K500, or the new superconducting cyclotron (Fig. 1). The K150 cyclotron with high intensity stable isotope beams will be used as a driver for production of radioactive species, while the K500 cyclotron will serve as a post-accelerator.

\section{ION PRODUCTION}

The upgraded facility will depend on a number of ion sources - three electron-cyclotron-resonance ion sources (ECRIS), a multi-cusp ion source, and two ion guides. In addition low intensity, low-charge-state ions sources will be used to help tune the production of high-charge-state RIBs. Although the two cyclotrons will often independently supply beams, the components will be listed according the sequence for production of accelerated RIBs.

\footnotetext{
a) Contributed paper, published as part of the Proceedings of the 14th International Conference on Ion Source, Giardini-Naxos, Sicily, Italy, September, 2011.

b)Electronic mail: tabacaru@comp.tamu.edu.
}

\section{A. Negative ion source}

Since a large part of the RIB program involves high intensity proton and deuteron driver beams from the K150, a negative ion source with extraction by stripping was considered in order to reduce activation of the cyclotron. Following a similar program at the University of Jyväsklylä (JYFL) Cyclotron Laboratory, a filament excited, multi-cusp ion source was decided upon. A spare positive-ion multi-cusp source was purchased from JYFL. With design and construction help and support from JYFL, it was reconfigured for negative ion production by separating the discharge region with permanent-magnet fields in addition to adding a permanentmagnet electron-filter. In 2010, the source was mounted on the injection line for the $\mathrm{K} 150$ above the $90^{\circ}$ analysis dipole used with ECR2 (Fig. 2). With limited operating time, the source has produced $1.5 \mathrm{emA}$ of $\mathrm{H}$ - ions and has injected both $\mathrm{H}$ and $\mathrm{D}$ - into the K150 cyclotron.

\section{B. ECR2 ion source}

Also injecting into the K150, ECR2 is a $14.5 \mathrm{GHz}$ ECRIS. ${ }^{1}$ The source was configured to have fields comparable to the LBL AECR-U (Ref. 2) ion source, but with a larger plasma chamber, since ECR1 type coils and steel yoke from an already existing source were used to save time and costs. ECR2 was chosen for the K150 because of the high intensity requirements of the $\mathrm{K} 150$ as the driver producing reasonable quantities of rare species. To date, ECR2 has produced $168 \mathrm{e} \mu \mathrm{A}$ of ${ }^{16} \mathrm{O}^{7+}, 69 \mathrm{e} \mu \mathrm{A}$ of ${ }^{40} \mathrm{Ar}^{12+}, 48 \mathrm{e} \mu \mathrm{A}$ of ${ }^{40} \mathrm{Ar}^{13+}$, $27 \mathrm{e} \mu \mathrm{A}$ of ${ }^{40} \mathrm{Ar}^{14+}$, and $5.0 \mathrm{e} \mu \mathrm{A}$ of ${ }^{197} \mathrm{Au}^{35+}$. The gold was introduced via a fixed sputtering device inserted into the plasma chamber through a radial slot. For all these results, the extraction voltage was $10 \mathrm{kV}$, and the microwave power level was 1.3 to $1.5 \mathrm{~kW}$.

\section{Light-ion guide and heavy-ion guide}

The light-ion guide (LIG) will be used for the production of neutron-deficient RIBs. The driver beams from the 


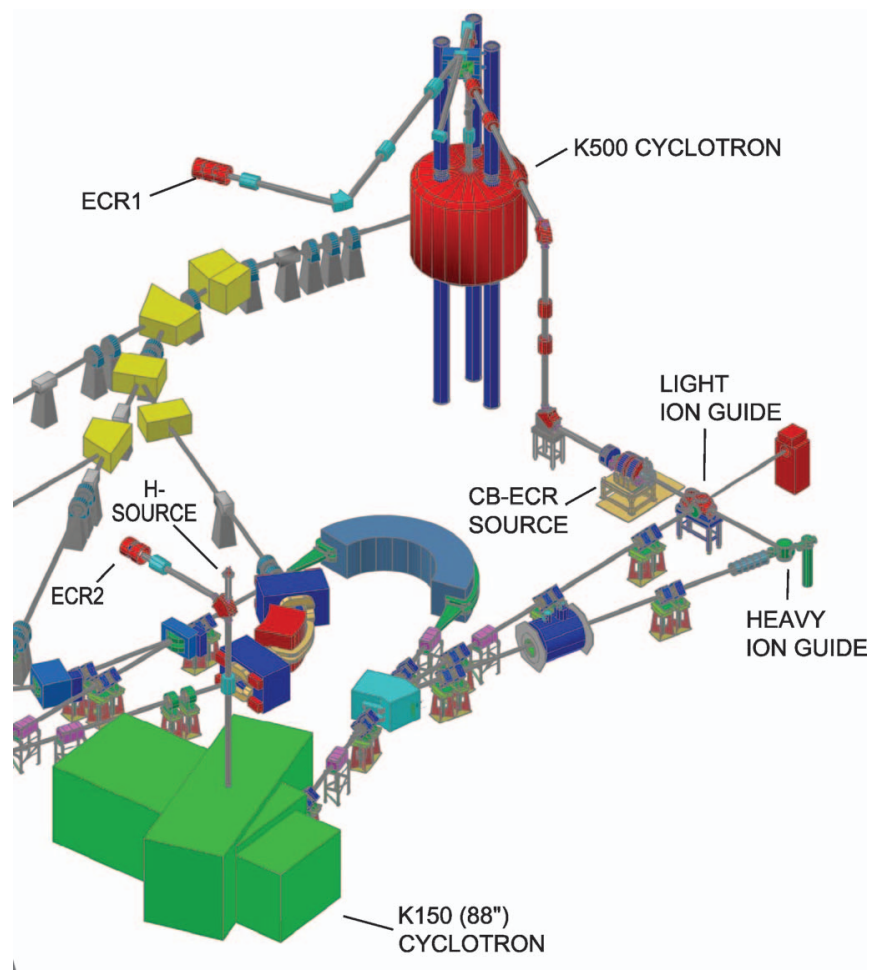

FIG. 1. (Color online) Layout of the Coupled Cyclotron Facility.

K150 will be protons, deuterons, and possibly alphas. The device features three-stage, differential pumping and an RF-only hexapole for high efficiency transfer of $1+$ radioactive ions to the charge-breeding stage.

The principle of operation is the following: a primary beam from the K150 cyclotron interacts with a production target placed in the gas cell. A continuous flow of helium gas maintains a constant pressure of 500 mbar maximum in the cell. Recoils are thermalized in the helium buffer gas and ejected from the cell within the gas flow through a small exit hole. The positively charged recoil ions $(1+)$ are guided into an up to $2.5 \mathrm{~m}$ long, rf-only hexapole. In this manner, the ions are transported into a low-pressure region before being accelerated to the voltage of the charge-breeding ECRIS.

The LIG has demonstrated transport of ions of radioactive product ions from an open ${ }^{228}$ Th source. ${ }^{3}$ Alphas from the daughter ${ }^{216}$ Po with a half life of $145 \mathrm{~ms}$ were detected at the end of the hexapole at a rate of 100 per second.

For production of radioactive ions from collisions with heavier species, the heavy-ion guide is being planned starting with a separate beam line from the K150. Products from such collisions will be separated and focused onto a helium-filled cell using a superconducting solenoid. The cell, which is being designed and constructed in collaboration with Argonne National Laboratory, slows, focuses, and extracts singly charged ions via collisions with the helium gas and carefully aligned dc and rf electric fields.

\section{Charge-breeding ECR ion source}

The ECR ion source that will be devoted to chargebreeding the radioactive ions (CB-ECRIS) produced by the ion guides and injecting them into the K500 cyclotron was

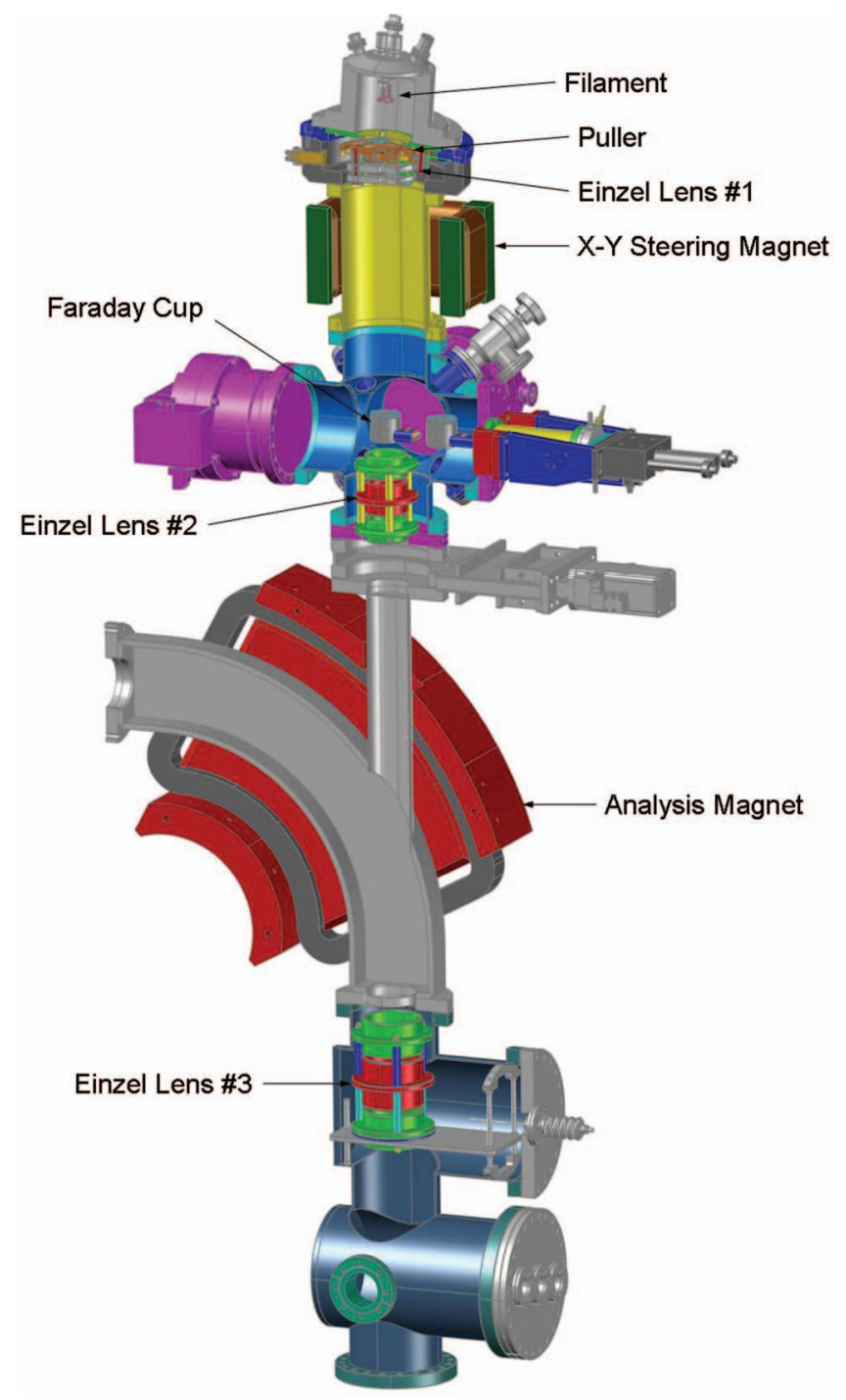

FIG. 2. (Color online) Mounting position of multi-cusp ion source.

delivered in 2007. It was designed and built by Scientific Solutions of San Diego, California with a Phase I and Phase II Small Business Innovative Research grants from the U.S. Department of Energy ${ }^{4}$ and first operated in 2009..$^{5}$ Two large coils supply the axial mirror magnetic field, and a surrounding Halbach type hexapole, assembled with Nd-Fe-B permanent magnets, provides the radial mirror field. The plasma chamber is formed by a water-cooled aluminum liner. The source is of medium volume and operates at $14.5 \mathrm{GHz}$ with the possibility of adding a lower second frequency later.

To test the charge-breeding capability of the CB-ECRIS, a beam of stable $1^{+}$ions is injected into the plasma chamber from a commercial ion gun made by HeatWave Labs and capable of producing $1 \mu \mathrm{A}$ of $1+$ current from the alkali elements, $\mathrm{Li}, \mathrm{Na}, \mathrm{K}, \mathrm{Rb}$, and $\mathrm{Cs}$. The ion gun was initially mounted directly on the injection flange of the CB-ECRIS, but after an unsuccessful attempt at injection it was found that the beam from the ion gun was significantly off-axis and not entering the CB-ECRIS. An electrostatic steerer has been built, following a design used by the Argonne ATLAS charge-breeder, ${ }^{6}$ and has been demonstrated to be able to cen- 
ter the beam. A multi-pin Faraday Cup array has been built to verify the centering of the injected beam. New attempts at charge-breeding are awaiting the final configuration of the ion-guide cave.

\section{E. ECR1 ion source}

Injecting into the K500 cyclotron, ECR1 is a $6.4 \mathrm{GHz}$, high-B mode ECRIS with an aluminum plasma chamber configured as an upgrade in 1995 (Ref. 7) to an existing ECRIS constructed in 1989. With radial access to the plasma chamber, it is possible to run a wide variety of species using gases, low-vapor-pressure materials, sputtered solids, and solids vaporized in either a low-temperature or high-temperature oven. ${ }^{8,9}$ For the eventual acceleration of radioactive isotopes in the K500, ECR1 will provide stable analog beams for the initial cyclotron tuning.

\section{STATUS}

Up to $24 \mathrm{e} \mu \mathrm{A}$ of $30 \mathrm{MeV}$ protons have been extracted from the $\mathrm{K} 150$ after stripping of the internal $\mathrm{H}^{-}$beam. Higher, more stable intensities will follow after the planned installation of LHe cryopanels in the K150. The existing vacuum now in the range of low $10^{-6}$ torr will be improved up to $5 \times 10^{-7}$ torr with the installation of the cryopanels. The ionguide cave has been completely enclosed with new radiation shielding, and an aluminum beam-dump has been located opposite the light-ion guide. A $10 \mathrm{e} \mu \mathrm{A}$ beam of protons has been delivered to the beam-dump so that radiation levels could be measured outside the shielding.

Assembly of the components necessary for operating the LIG and the CB-ECRIS remotely and for isolating the LIG at the extraction voltage of the CB-ECRIS is ongoing. In addition, assembly of the injection line from the CB-ECRIS to the K500 is beginning. Calculations indicate that with the efficiencies expected up to $10^{4}$ to $10^{5}$ particles/s of proton-rich species of RIBs generated by the LIG could be delivered to target by the K500.

The K150 has accelerated high-charge-state oxygen ions from the ECR2 ion source, but serious efforts for intense beams of heavy ions from the cyclotron are waiting on installation of the internal cryopanels and on various repairs to the cyclotron. Meanwhile, in an effort for higher intensities from the source, ECR2 is being equipped for two-frequency heating with the addition of $11 \mathrm{GHz}$ microwaves from a $400 \mathrm{~W}$ travelling-wave-tube transmitter.

\section{ACKNOWLEDGMENTS}

The assistance and support of O. Tarainen, T. Kalvas, T. Ropponen, and O. Steczkiewicz from JYFL has been invaluable in the construction and commissioning of the multicusp, negative-ion source.

${ }^{1}$ D. P. May, F. P. Abegglen, G. J. Derrig, and R. S. Olsen, Chinese Physics C 31(S1), 105 (2007).

${ }^{2}$ C. M. Lyneis, J. Phys. (Paris) Colloq. 50, CI-689 (1989).

${ }^{3}$ G. Tabacaru, D. P. May, and J. Ärje, in Proceedings of the 19th International Workshop on ECR Ion Sources, Grenoble, France, 2010, p. 55, http://lpsc.in2p3.fr/JACoW_files/ECRIS10/papers/MOPOT010.PDF.

${ }^{4} \mathrm{~W}$. D. Cornelius, in Proceedings of the 18th International Workshop on ECR Ion Sources, Chicago, IL, 2008, p. 185, http://cern.ch/AccelConf/ecris08/papers/wecob01.pdf.

${ }^{5}$ D. P. May, G. Tabacaru, F. P. Abegglen, and W. D. Cornelius, Rev. Sci. Instrum. 81, 02A901 (2010).

${ }^{6}$ R. C. Vondrasek, R. Scott, J. Carr, and R. C. Pardo, Rev. Sci. Instrum. 79, 02A901, 2008.

${ }^{7}$ D. P. May, Rev. Sci. Instrum. 69, 688 (1998).

${ }^{8}$ R. Harkewicz, P. J. Billquist, J. P. Greene, J. A. Nolen, and R. C. Pardo, Rev. Sci. Instrum. 66, 2883 (1995).

${ }^{9}$ H. Koivisto, J. Ärje, and M. Nurmia, Nucl. Instrum. Methods Phys. Res. B 94, 291 (1994). 